\title{
Applying Rice Seed-Associated Antagonistic Bacteria to Manage Rice Sheath Blight in Developing Countries
}

\author{
Twng Wah Mew, Bart Cottyn, Raymond Pamplona, Helen Barrios, and Li Xiangmin, Entomology and Plant \\ Pathology Division, International Rice Research Institute, DAPO Box 7777, Metro Manila, Philippines; Chen Zhiyi \\ and Lu Fan, Institute of Plant Protection Research, Jiangsu Academy of Agricultural Sciences, China; Nongrat Nil- \\ panit and Parkpian Arunyanart, Division of Plant Pathology and Microbiology, Department of Agriculture, Thai- \\ land; Pham Van Kim, Cantho University, Cantho, Vietnam; and Pham Van Du, Cuu Long Rice Research Institute, \\ Omon, Cantho, Vietnam
}

\begin{abstract}
Mew, T. W., Cottyn, B., Pamplona, R., Barrios, H., Xiangmin, L., Zhiyi, C., Fan, L., Nilpanit, N., Arunyanart, P., Kim, P. V., and Du, P. V. 2004. Applying rice seed-associated antagonistic bacteria to manage rice sheath blight in developing countries. Plant Dis. 88:557-564.

One promising area of disease management for resource-poor farmers that emerged in recent years in developing countries is the potential of biological control. Biological control agents (BCAs) were found to be ubiquitous in the rice ecosystem. Seed bacterization with BCAs appeared to promote plant growth. BCAs showed efficacy on sheath blight (Rhizoctonia solani AG 1) but produced inconsistent results over time in the field using it alone. The control efficiency ranged from 50 to over $90 \%$, with a high variance. To improve the efficacy, a half-dose of a commonly used fungicide, like Jingangmycin in China and Validamycin in Vietnam, was introduced to mix with BCAs and was found to be effective, and it reduced the variance of the field performance tests. To scale up the BCA technology for resource-poor farmers, a participatory approach, engaging the farmers to evaluate the product, was initiated in China and Vietnam. The BCA strain that is indigenous at a locality is mass produced at the research institution based on the total area required for application, as relayed by the farmers to extension workers. The demand by farmers would serve as the basis for the amount to be produced and for delivery to the rice farmers who were participating in the trials and, later, to those farmers who ordered the product. This process alleviates BCA storage and shelf-life problems. Data from the field performance trials also were used by the researchers to apply for registration for commercial use of BCAs. Scaling up to extend the BCA technology to more rice farmers as an integral part of their pest management scheme, in particular, and crop management practices, in general, is foreseen in the near future.
\end{abstract}

\section{Why Biological Control?}

The rice disease profile has changed in response to changing rice production situations, such as greater use of direct seeding and planting of new resistant cultivars. These changes are due to reduction in arable land area, fast population growth, and the need for greater efficiency and productivity. As yields increase, greater amounts of nitrogen fertilizer now are applied in intensive rice-production systems. The excess nitrogen leads to a luxuriant vegetative growth and a dense crop canopy, which favor disease development. Rice disease always has been a significant factor in rice supply. Historically, severe

Corresponding author: T. W. Mew
E-mail: T.Mew@ cgiar.org

Accepted for publication 1 December 2003.

Publication no. D-2004-0218-010

๑) 2004 The American Phytopathological Society disease epidemics have led to serious food shortages (18). Sheath blight, caused by an aerial form of Rhizoctonia solani AG 1 , is one of the newly emerged rice diseases that threaten the stability of rice production (3). Although it seldom causes total crop failure, sheath blight accounts for 6 to $10 \%$ loss annually under high-input and highproduction environments in both temperate and tropical regions of Asia (25). This degree of loss is substantial.

Sheath blight occurs under conditions of a temperature range of 23 to $35^{\circ} \mathrm{C}$ and high humidity $(>95 \%)$ in the crop canopy. The dense crop canopy provides the favorable microclimate for disease development (18). It has become a dominant disease problem because of increased crop intensity, increased fertilizer use, and close plant spacing (24), which are common rice-growing practices in modern production.

The pathogen survives from one crop season to another through sclerotia and mycelia in plant debris and other weed hosts in tropical environments (11). In temperate environments, the primary source of inoculum is the sclerotia produced in previous rice crops (12). Both sclerotia and mycelia survive in infected plant debris. If survival of the pathogen is through sclerotia dropped in the field during harvest, these sclerotia will infect the next rice crop. Before maturity, the sclerotia are nonbuoyant. They then become buoyant as they mature (13). The buoyant sclerotia in the field would attach to the rice plant, germinate, and cause initial infection. The sclerotial distribution pattern is either clumped or in a manner of negative binomial distribution; the pattern tends to be more random after land preparation. In the tropics, immediately after harvest or before land preparation, the estimated number of sclerotia is about 2 to $3 \mathrm{million} / \mathrm{ha}$. After land preparation, the estimated number may be lower than that observed after harvest, but it still maintains a number of about 2 million (S. Z. Yin and T. W. Mew, unpublished data). Hence, land preparation may have a role in reducing sclerotial number. We have noted differences in sclerotial dimension and viability in tropical rice environments. The size of the sclerotia of $R$. solani AG 1 ranges from 1 to $3 \mathrm{~mm}$ in diameter. Infectivity was positively related to size of sclerotia. The most frequently collected sclerotia had a size of $1 \times 1 \mathrm{~mm}$. The viability of the sclerotia also varies. The viability of sclerotia recovered from a tropical rice soil subjected to intensive cultivation was less than $50 \%$. Among the nonviable sclerotia, more than $80 \%$ were bacterialized with different kinds of bacterial species, and only a very few of them were colonized by fungi (S. Z. Yin and T. W. Mew, unpublished data). Hence, bacteria may be responsible for the fungistatics of sclerotia in tropical rice fields.

There is no effective way to control sheath blight. A few fungicides are available and chemical control with these fungicides is widely practiced, mostly in the temperate or subtropical environments in countries such as China, Japan, Korea, and 
Vietnam. It offers an immediate solution when an epidemic occurs (10). However, the use of chemicals by small rice farmers is not sustainable and its impact on environmental protection is well understood (20). Furthermore, the efficacy of a few fungicides, such as Jingangmycin (10), which was used in China for the past 30 years, gradually has been reduced as farmers continue to increase the dosage in field application in order to obtain the desired effect. In other countries in the tropics, however, chemical control is rarely practiced.

Host plant resistance has been the backbone of disease management. It is an integral component of modern rice production in South and Southeast Asia. Yet, in spite of continuous effort to develop and deploy new rice cultivars with new yield potential and new genes for resistance, diseases continue to pose a threat as development of host plant resistance is targeted to only a very few diseases with high epidemic potential. Until recently, the disease management options available to most resource-poor rice farmers largely were dependent on cultivars that are resistant to a few diseases. The useful life of resistant cultivars is shortened when the population of the pathogen has adapted to its resistance, and occurrence of minor pathogens increased in importance as new rice cultivars were deployed and new cultivation methods were modified to suit these new cultivars. The actual yields brought about by the new resistant cultivars may not be realized and the resistance would not last long enough to sustain rice production for resource-poor farmers. It is essential that we search for other ways to manage rice diseases. As we have shown, bacteria in the rice fields affected the viability of the sclerotia of $R$. solani AG 1 . The option of exploring the potential of these naturally occurring bacteria in the rice field looked promising $(4,5)$. Initially, the conventional approach was used to isolate and test the biological control agent (BCA) in a controlled environment, in the greenhouse, and in the field. The results pointed to a dilemma. One possibility is to continue to improve the available strains or search for new strains of BCAs, which can perform similarly to chemical fungicides; however, biological control of rice diseases for rice farmers in developing countries would be a remote technology in rice production. The other option is to re-examine the strategy and change our approach in biological control using BCAs. In this article, we describe and outline our approach on biological control to combat rice diseases. Although the scope of biological control does not include only sheath blight, we will use this particular target disease to illustrate our strategy and the system developed for biological control of rice diseases with resource-poor farmers in mind.

\section{Designing the Project}

As indicated earlier, bacteria in the field affect the viability of the $R$. solani sclerotia, and some of the sclerotia are colonized by the bacteria. Initially, we followed the standard approach of isolating antagonistic bacteria from sclerotia as well as from other sources within the paddy systems: paddy water, rice plants (healthy and diseased plant parts), and rice seed. Clearly, the rice ecosystem is rich in bacteria (Table 1). A large proportion of the bacteria are antagonistic to $R$. solani, Fusarium moniliforme, and Pyricularia grisea $(6,9,14-16)$. When these antagonistic bacteria were tested, initial results were promising $(14,15)$; however, in subsequent experiments using either single strains or a combination of strains, the results were inconsistent. Although this could be due to the complex interactions among the BCAs, the crop, the pathogens, and the crop production environments (1), it did point out the difficulty for resource-poor farmers to apply biological control technology. We need to have a better understanding of the mechanism of BCA disease development process, and a different strategy to formulate BCAs and scale up the technology. Conventional research focused on improving the target strains to make them more effective and competitive. If this did not work, then new and more strains would need to be isolated. Antagonistic bacteria were isolated and introduced from unre- lated ecosystems; the levels of establishment and survival of the introduced antagonistic bacteria were expected to be low and alien to the local environments. Rice ecosystems have been shown to be abundant in microorganisms; therefore, the best possibilities may be the use or stimulation of indigenous bacteria associated with the rice crop or in fields where rice is to be grown. Strains obtained from native sites should be more competitive ecologically than those introduced (29). Because of many years of isolation in a network of many scientists from diverse rice-growing environments, we have not come up with the "best" strains for rice disease management (15). When we fail to isolate or identify the most effective BCA strains, we return to the "drawing board," re-examine the purpose of our project, and reassess the process and pathway to reach our goal (Fig. 1).

Our research aimed at developing a product compatible with farmers' crop and disease-management practices on a commercial scale. Then, issues regarding the design of the project pathway leading to technology development, technology diffusion, and eventual technology adoption were addressed. Taking this approach, research focused on finding answers to such questions as: "How are BCAs different from fungicides?" "What can BCAs offer that fungicides cannot?" "Can BCAs function like chemical fungicides in disease control? If not, could we improve the efficacy of BCAs through formulation?" In the past decades, research on biological control in less developed countries often was seen as dissociated from end-users, the farmers or the growers. Knowing the rice farmers' needs and how they practice crop management and disease control would be useful to guide product development and in the definition of our research objectives. Unlike chemical fungicides, storage and shelf life are two important factors to consider in BCA technology development. Even in the end, when we have a product in our hand, we still need to ask: "Do our farmers have enough confidence in the product so that the technology of biological control could be adopted immediately?" Research may come up with a product, but the product only ends up in the laboratory shelf. "Should we market the BCA product in the same manner as we sell fungicides?"

With all these questions in mind, we set the objectives of our research on BCAs for sheath blight management to (i) study the short- and long-term effects of BCAs on the epidemic process and development of sheath blight, and (ii) improve the efficacy of BCAs with a dose of a commonly used fungicide (e.g., Jingangmycin) in BCA formulation. The objective of adding the fungicide was to slow the infectivity of the pathogen. The aim was to gradually reduce chemical usage. 


\section{Research}

With some of the key questions raised in the above section, our research was designed to evaluate the effect of BCAs, in mixture with a half dose of Jingangmycin in China and Validamycin in Vietnam, on sheath blight management. We also hypothesized that BCA should function to reduce the focal point expansion and the number of disease foci of the disease in short-term and long-term effects, respectively. We viewed BCAs, therefore, as an internal resource of a rice ecosystem. Thus, biological control of rice diseases using local strains of BCAs is regarded as managing the existing resource.

Abundance of BCAs in rice ecosystems. Rice plants are the natural habitat of many microorganisms. The quantity and composition of these microorganisms are not well known. Abundance of these bacteria varies, depending on sources of seed, status of seed health, and whether germinated or whole seed before germination are involved (6; B. Cottyn and T. W. Mew, unpublished data). The types of bacteria include pathogenic and nonpathogenic forms of different genera (Table 1). Obviously, those causing a harmful effect on the growth of the plant are classified as pathogens. Among the pathogenic forms, there are distinct plant pathogens and there are others classified as opportunistic pathogens that cause plant diseases when the host plants are under stress. Field evaluation of selected strains indicated a greater disease reduction at harvest with an application of a mixture of a Bacillus sp. and Burkholderia cepacia, compared with individual strain application in rice cultivar IR72 in the 1994 dry season (Fig. 2). These strain combinations, which gave better disease control than treatments with single strains, seemed to exhibit synergism. However, this synergistic effect was not observed consistently in all the treatments and in subsequent tests, even though the data indicated better biocontrol activity in selected strain mixtures than individual strains (T. W. Mew, unpublished data). Bacillus spp. produced inhibitory substances $(9,22)$ and phytohormones that induced resistance (28). Pseudomonas putida and Burkholderia cepacia were producers of secondary metabolites 2,4diacetylchloroglucinol and pyrrolnitrin, respectively (22). The presence of mixtures of metabolites may enhance the suppressive effect on the target pathogen (19). Hence, in a strain mixture, compatibility of BCAs is an important consideration.

In isolating BCAs, we focused on bacteria for potential use in paddy rice under anaerobic conditions with standing water during crop growth. Using common laboratory culture media, we isolated BCAs from samples of paddy water, rice plants, straws, and in or on seeds. Although some of them are pathogenic, many of these bacteria establish large populations with no apparent effect on the plant. A few of them exhibit properties of antagonistic effects on fungal and bacterial pathogens. There were more diverse groups among the nonpathogenic forms from those possessing antagonistic effects on selected rice fungal pathogens, such as $R$. solani, $F$. moniliforme, Pyricularia grisea, Sarocladium oryzae, and others, than those with a plant growth promotion effect, as shown by a rice seedgerminating technique $(6 ; \mathrm{B}$. Cottyn and T. W. Mew, unpublished data). We demonstrated the growth promotion effect of the selected strains in field experiments under different rates of nitrogen fertilizers (Fig. 3). Again, such traits of the BCA were not duplicated in subsequent experiments in the same fields with the same strains or strain combinations. Among the grampositive bacteria, Bacillus spp. were common and were detected more often from the whole seed before germination than from germinated seed and mature plant parts, either senescent leaves or leaves with injury. When seed began to germinate, the number of Bacillus spp. decreased but that of gram-negative bacteria increased (16). Strains of B. subtilis, B. laterosporus, and $B$. pumilus were among the promising BCAs of this group (23).

The number of gram-negative bacteria varied from one site to another, and from one season to another. During seed germi- nation, the flora of seed-associated antagonistic bacteria change. The few wellestablished BCAs (e.g. P. putida, Pseudomonas fluorescens, and Burkholderia cepacia) were isolated from both temperate and tropical environments. Serratia marcescens and Erwinia herbicola also were detected in rice plants $(22,23)$.

In terms of the effect on seed germination and suppression of seedborne $F$. moniliforme, the causal pathogen of bakanae, these antagonistic bacteria were classified into three groups: those that promoted seed germination and enhanced seedling vigor, those that had no effect on seed germination, and those that had a deleterious effect on seed germination $(15,21)$. Evidently, these microorganisms form a part of the bacterial community associated with the rice ecosystem.

Function of BCAs in disease management. The potential of BCAs in the first group mentioned above (i.e., promoting rice seed germination and enhancing rice seedling vigor) was tested and promising results were obtained from initial greenhouse and field tests. $B$. cepacia strain In-b-6854 reduced sheath blight incidence at maximum tillering and at harvest in direct-seeding rice. This suppressive effect could be a carryover of bacterialized seed directly sown in the field with less rhizosphere disturbance. It was

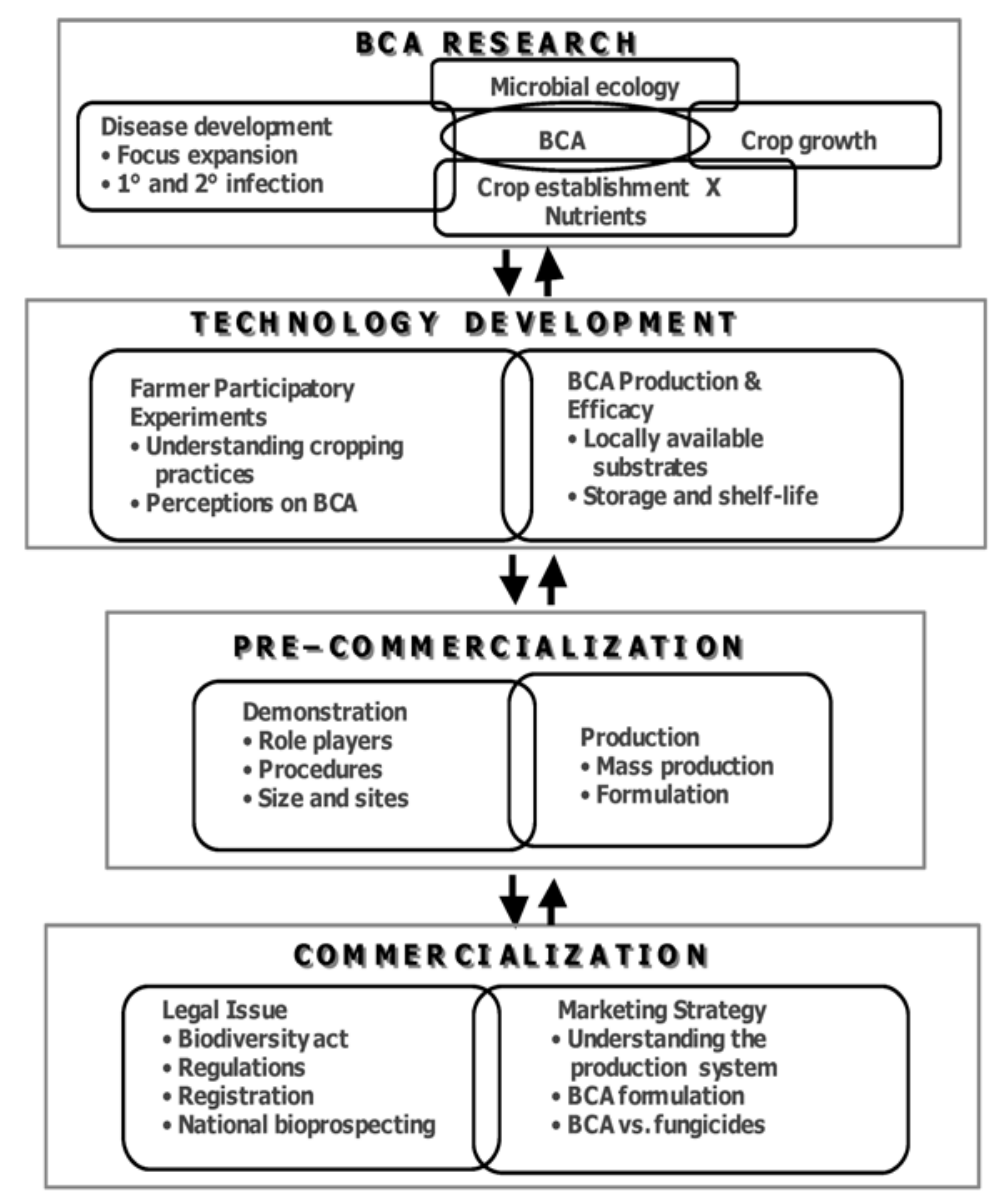

Fig. 1. Project design of biological control of rice sheath blight from research to commercial application. 
assumed that, in direct-seeded rice, the contact between the root system and BCA would be maximized; whereas, in transplanted rice, uprooting and transporting the bacterialized seedlings from the seedbed to the main field might reduce the BCA-root system contact and expose the BCA to different macro-environments. Hence, the use of BCAs as a seed treatment could be more efficient in direct-seeded rice. Colonization of plant parts from healthy and diseased plants differed among strains, species, and genera (X. Li and T. W. Mew, unpublished data). Seed bacterization promoted plant growth based on seedling vigor and seed germination (15). Performance of disease control was related to strains instead of species. An understand-

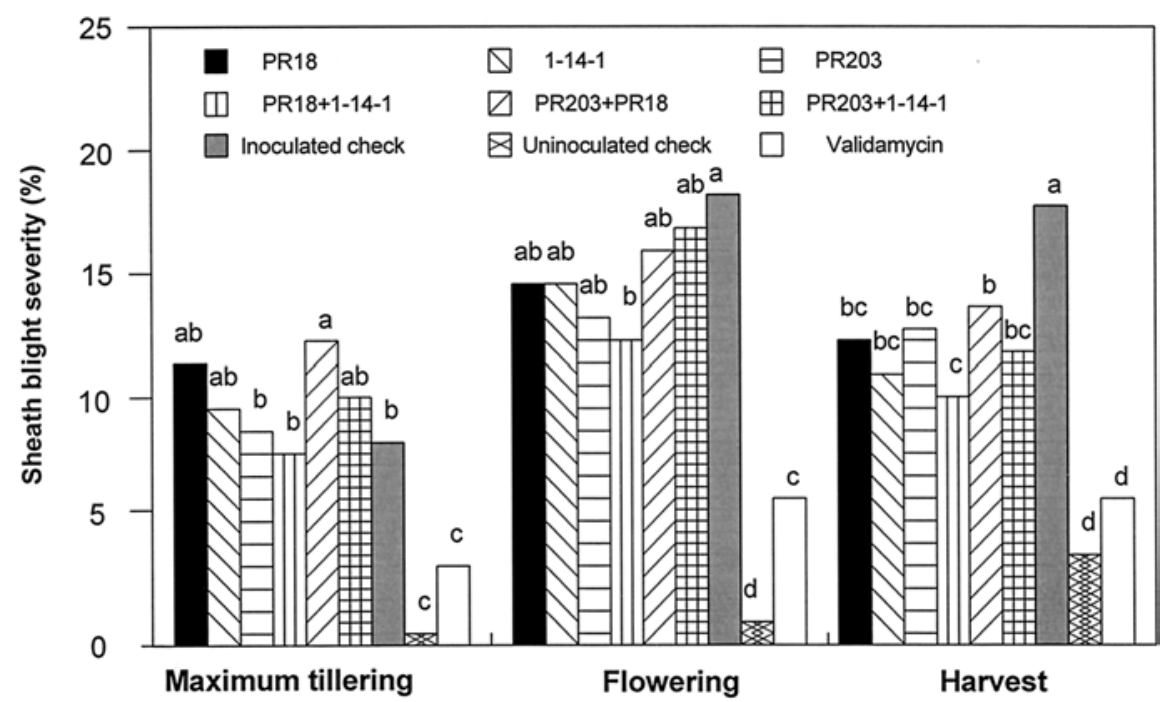

Fig. 2. Sheath blight severity in rice cultivar IR72 at various biological control agent (BCA) treatments in an experiment conducted during the 1994 dry season at the Philippine Rice Research Institute. PR18 and PR203 are Bacillus spp. strains. The Burkholderia cepacia strain used is 1-14-1.

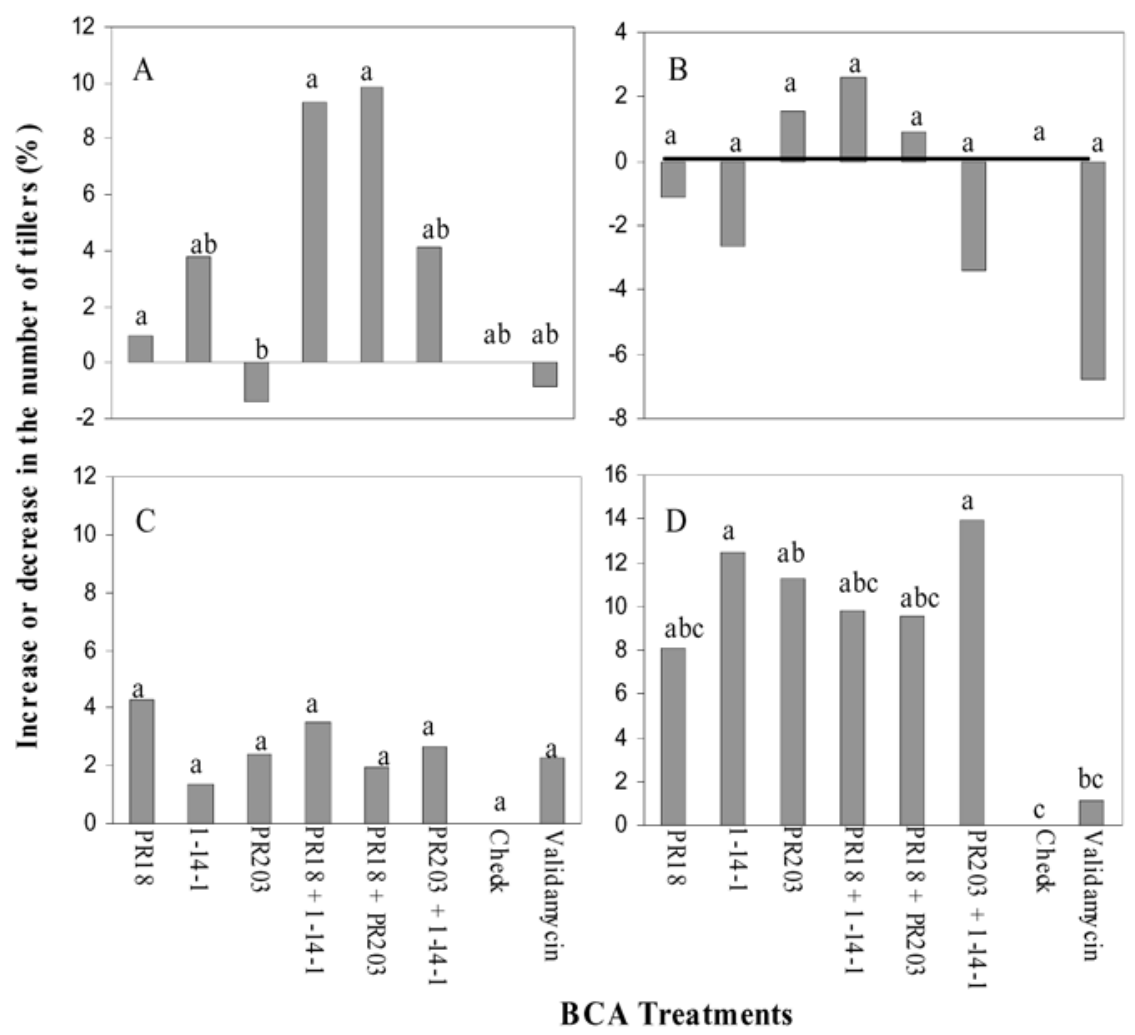

Fig. 3. Effects of biological control agent (BCA) treatments on the increase or decrease in the number of tillers of rice cultivar IR72 at various amounts of applied nitrogen fertilizer; A, 0, B, 90, C, 120, and $\mathbf{D}, 180 \mathrm{~kg} / \mathrm{ha}$ during the 1994 wet season at the International Rice Research Institute. PR18 and PR203 are Bacillus spp. strains. The Burkholderia cepacia strain used is 1-14-1.

ing of indigenous BCA population and its function in the disease development process is useful to identify the right strains and deploy them at the right crop developmental stage. For field application, the key intervention point in disease development offers the maximum effect of biological control.

A significant reduction in sheath blight severity due to BCA application was observed at flowering and at harvest, regardless of the rates of nitrogen fertilizer used during the dry-season crop. This reduction in sheath blight coincided with the application of BCAs. It was noted that sheath blight lesions initially appeared 5 days after pathogen inoculation, followed by formation of runner mycelia on the surface. A spray application of BCAs at this stage seemed to strengthen the BCA-R. solani mycelium contact, resulting in less disease spread. The gap between plants in transplanted rice eased the efficiency of BCA sprays, allowing a higher probability of lesion-BCA contact. In direct-seeded rice, the dense leaves trapped most of the sprays, thus making BCA-lesion contact less possible. The results suggested that BCA reduced the inoculum efficiency for secondary spread of sheath blight from plant to plant or from leaf to leaf. Thus, the function of BCA was to restrict the disease spread or focal point expansion in the process of sheath blight development. The BCAs under the present study all were saprophytes by nature; therefore, it is unlikely that they could function to reduce sheath blight severity (measured by lesion length or relative lesion height) once $R$. solani had entered the plant tissues. This observation was further supported by an experiment conducted in 1997 at the International Rice Research Institute Farm. In these experiments, sheath blight incidence was different among plots with and without BCA treatments initially. As crop growth advanced, sheath blight continued to develop rapidly. Disease assessment and visual observation did not reveal significant differences between the treatments. Then a strong typhoon made all the crops lodged a month before harvest. At harvest, as plants laid in the field, the difference among treatments was obvious based on secondary infection that took place during the time when the plants were lodged (Fig. 4). This observation suggested that the effect of BCAs was more effective in preventing secondary instead of primary infection because the timing of application to protect the crop from primary infection was more unpredictable. The occurrence of antagonistic bacteria might inhibit the infection of the sclerotia.

To enhance and stabilize the efficacy of BCAs, a dose of a commonly used fungicide added into the formulation was important. The purpose of BCAs plus a halfdosage of fungicide was to let the fungicide slow down or stop the pathogen from 
advancing the infection process; this would provide ample time for the BCA to adjust its full capacity and express its biocontrol activities. When a half-dose of Jingangmycin was added to BCA strain B-916, the results were consistent in suppressing sheath blight development in the field at all testing sites in Jiangsu Province, China (Table 2).

Thus, the functional relationship of BCAs to sheath blight ( $R$. solani AG 1 ) development was assessed in terms of the reduction in number of disease foci, lesion development, and focal point expansion. Experiments were set up in sheath blight hotspot areas under continuous rice cropping systems, and application of different formulations of BCAs (as a mixture in combination with a common fungicide) was done in Central Thailand. Our results suggested that the number of sheath blight foci decreased in fields where BCAs were applied in each cropping season over three to five seasons (Fig. 5), while incidence of sheath blight in neighboring fields remained high (17). In sheath blight management, BCA application, therefore, reduced the disease foci instead of achieving immediate disease control with a one-time application in a single cropping season. Application of BCAs in a continuous ricecropping system revealed the important role of BCAs in sustaining crop and disease management. Unfortunately, field experiments that evaluate the efficacy of BCAs often consider only the immediate effect of BCAs. The inconsistent results were related to finding out the perfect timing of an application, which was not always attainable in field conditions. Initial pathogen inoculum density and disease pressure under natural field conditions were variable and also influenced BCA efficiency. If the density of pathogen inoculum was too high, it was unlikely that BCAs would be able to suppress the rapid infection caused by the pathogen, especially under conditions favoring disease development. It is evident that an effective population density of BCAs was critical at the time of lesion initiation and expansion (1). To further verify the effect of BCAs on sheath blight development, our research set out to test the efficacy of BCAs on focal point expansion. The results seemed to indicate that, in the context of the sheath blight epidemic process, BCAs were more effective in reducing inoculum potential for new infection (i.e., secondary spread or the focal point expansion or disease foci) than in reducing sheath blight severity after the pathogen was established in the plant tissues (Fig. 6). The value of BCAs should target sustainable sheath blight management. Hence, application of BCAs for disease control should take into account the epidemic parameters of the target disease and be assessed for long-term rather than short-term effects, as seen with most of the fungicides (T. W. Mew, unpublished data and manuscript). Therefore, BCAs should not be treated like fungicides.

Research findings suggest complex interactions among the BCA, the crop, the pathogen, and the environment $(1,2,7,8,19$, $26,27)$. In a diverse and potentially more stable rhizosphere or phyllosphere community, the introduced strains of BCA need to be competitive in the plant environment in order to provide protection for consistent disease management. Sheath blight is a foliar disease but the pathogen may survive in paddy soil, plant debris, and weed hosts. The indigenous strains, reintroduced either singly or in mixture, need to be competitive in the environments of the plant surface and be established. The reality is that, if the initial inoculum of the target pathogen (in our case, $R$. solani AG 1 ) is abundant (high initial inoculum potential) and if the infection process is fast due to favorable environmental conditions (dense crop canopy with favorable temperature and humidity), it would be diffi- cult for the introduced BCA to function. An alternative method is the application of BCAs repeatedly during the critical period of disease development, when the host is vulnerable to pathogen invasion. In practical and in economical terms, this may not be feasible. Furthermore, when the pathogen is able to penetrate the host plant tissues, the introduced BCA as a saprophyte may no longer have the comparative advantage of protecting the rice plant against the invasion of the pathogen. Thus, application of BCAs for disease management needs an examination of the function of BCAs in the epidemic process and in terms of the timing of application.

The inconsistent results from the field trials seemed to suggest that introduction of BCAs alone might not be the best option. In the formulation, BCAs needed to be "supported" until the time they become functionally independent: when the population was high enough to outdo the pathogen or the action of the pathogen was re-

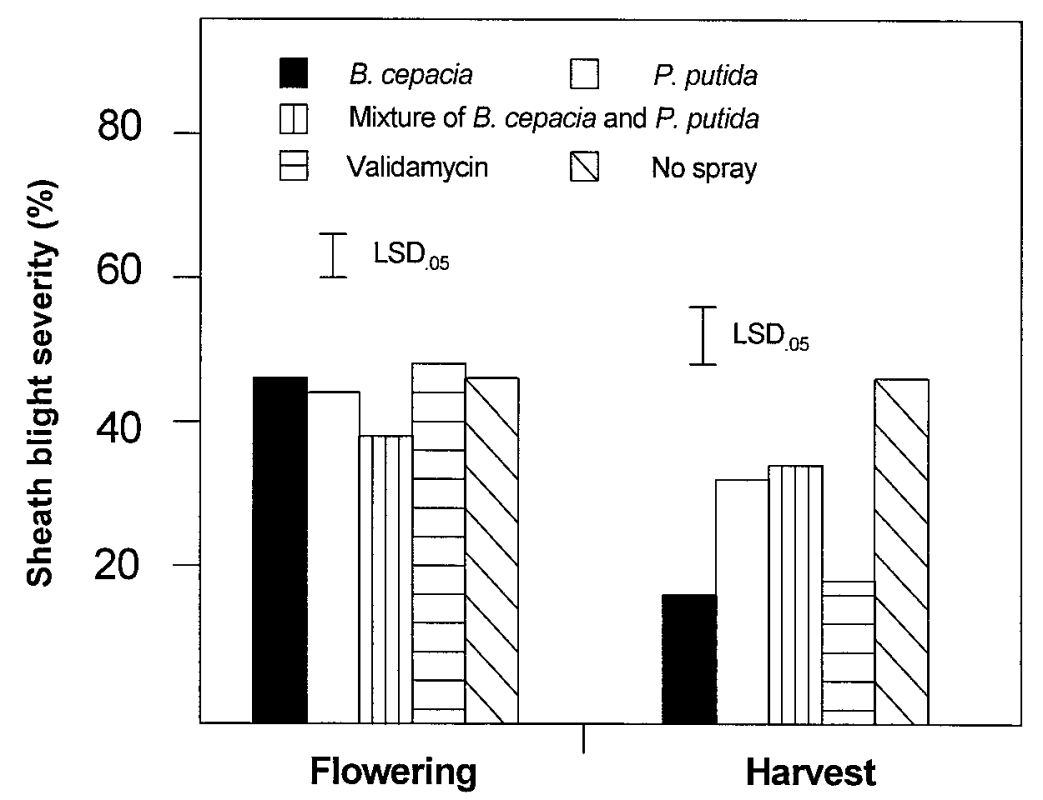

Fig. 4. Effects of biological control agent (BCA) treatments on sheath blight severity (\%) in directseeded rice cultivar IR72 at flowering and harvest in the 1997 wet season at the International Rice Research Institute.

Table 2. Effect of antagonistic bacterium Bacillus subtilis B-916 on incidence of Rhizoctonia sheath blight in farmers' fields at three sites in Jiangsu province, China

\begin{tabular}{lcccc}
\hline & & \multicolumn{3}{c}{ Disease incidence (\%) $^{\mathbf{z}}$} \\
\cline { 3 - 5 } Year, treatment & Dosage $\left(\right.$ liter ha $\left.{ }^{-1}\right)$ & Jurong & Jiangyan & Wujiang \\
\hline 1996 & & & & \\
B-916 & $3.75-4.50$ & $9.90 \mathrm{~b}$ & $10.50 \mathrm{~b}$ & $18.80 \mathrm{~b}$ \\
Jingangmycin & $3.75-4.50$ & $11.70 \mathrm{~b}$ & $9.60 \mathrm{~b}$ & $12.40 \mathrm{c}$ \\
Check & $\ldots$ & $29.40 \mathrm{a}$ & $42.80 \mathrm{a}$ & $48.80 \mathrm{a}$ \\
B-916 & 4.50 & $8.70 \mathrm{~b}$ & $\ldots$ & $\ldots$ \\
B-916 + Jingangmycin & $2.25+2.25$ & $\ldots$ & $2.10 \mathrm{~b}$ & $8.06 \mathrm{~b}$ \\
1997 & 4.50 & $11.00 \mathrm{~b}$ & $2.40 \mathrm{~b}$ & $4.61 \mathrm{~b}$ \\
Jingangmycin & $\ldots$ & $38.50 \mathrm{a}$ & $17.20 \mathrm{a}$ & $33.84 \mathrm{a}$ \\
Check & &
\end{tabular}

${ }^{\mathrm{z}}$ Each disease incidence datum is a mean of 10 replications. Means in a column within the same year having the same letter are not significantly different from each other $(P>0.01)$ by Duncan's multiple range test. 
tarded or slowed down by secondary metabolites produced by the BCA. The levels of establishment and survival of introduced antagonistic bacteria often were low; therefore, the best possibilities for the biological control of a soilborne pathogen causing a foliar infection might lie in the use or stimulation of indigenous BCAs from a paddy system in which the plant is grown. Antagonistic organisms that occur in the same ecological space and time frame (i.e., competing for the same nutrients) and play a role in the attraction of an infection may be the most attractive candidates (7). To find such antagonists, we need to understand the dynamics of the structure of the bacterial communities in the phyllosphere of the host plant (2) and buildup of microflora specific to a particular plant species and genotypes, as well as the plant devel- opmental stage of the plant parts (e.g., root, seed, and leaf). In our case, the BCA which was to be introduced into the canopy to protect plants against the pathogen, should, for practical reasons, be culturable and occur in high numbers from the paddy system. According to van Veen et al. (29), this may partly explain the difficulties and inconsistent results with the use of introduced BCAs. This seems to confirm our approach; in biological control of rice diseases, such as sheath blight, we have a causal organism that is a soilborne pathogen, but the infection and disease development always are associated with the aboveground plant parts. We need to rely on indigenous rather than introduced strains of BCAs. The greater the number of local indigenous strains from the rice-growing environments, the

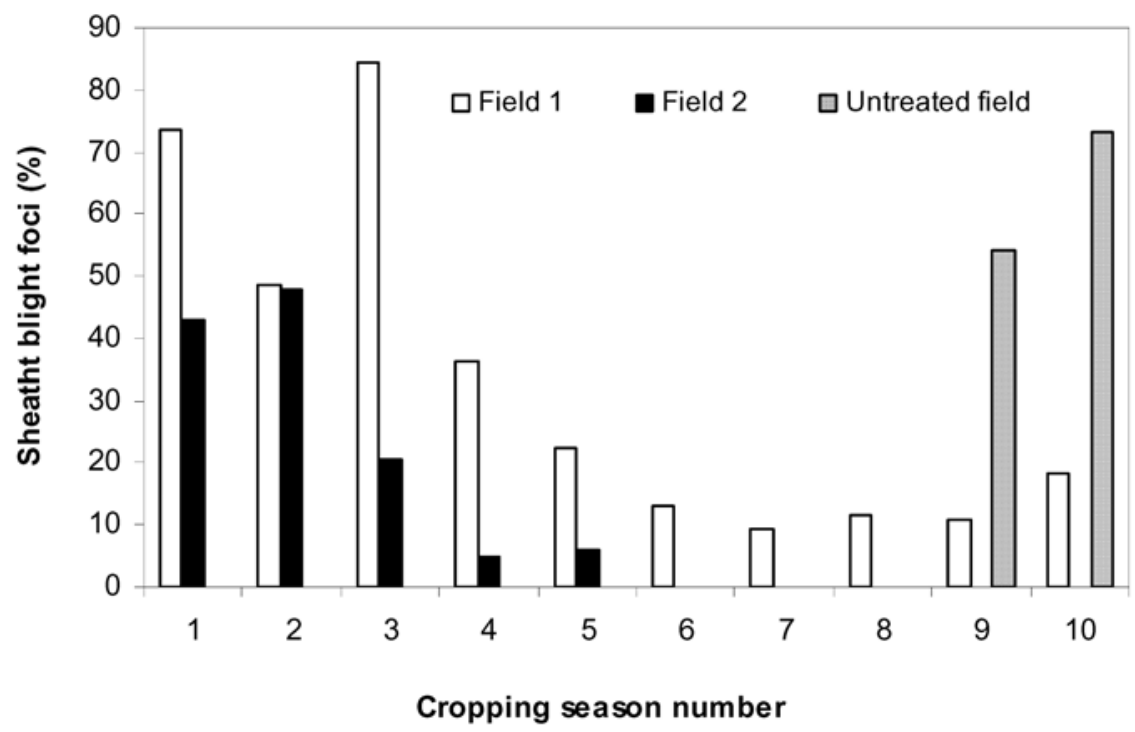

Fig. 5. Reduction of sheath blight foci in two field plots continuously applied with biological control agents (BCAs) in 10 cropping seasons from 1995 to 1999, Pathum Thani province, Thailand. better the choice and options; and biological control as a management tool becomes more sustainable. Even though indigenous, the BCAs adapt more slowly in the new environment compared with the fast-growing and versatile fungal pathogens. Initial support with a dosage of fungicide is essential to bring about the long-term effect of the BCA in disease management.

\section{Technology Development for BCA Production}

It would be difficult to market a product for disease management if the effect is not predictable and the results of field performance are variable. To solve this problem, we added a dose of a commonly used fungicide to the BCA formulation. The next issue is mass production. To scale up the BCA technology, we developed a decentralized BCA production system using "local indigenous strains for solving a local problem with the resources available locally." Local knowledge is very important in the developmental phase. The process took into account the farmers' participatory field evaluation, formulation to improve efficacy, and mass production system to ensure delivery.

The first step in farmers' participatory evaluation and testing was to identify the key sites and the key farmers. This was done based on local knowledge of the sites and historical data of the disease profiles maintained in the office of local governments. These were the basis for site selection for the impact of BCA technology. Operationally, we worked very closely with specialists at county agricultural and crop protection stations. They also identified the fields and key farmers to be engaged in the participatory experiments. In mass production, we collaborated with a fermentation plant associated with the
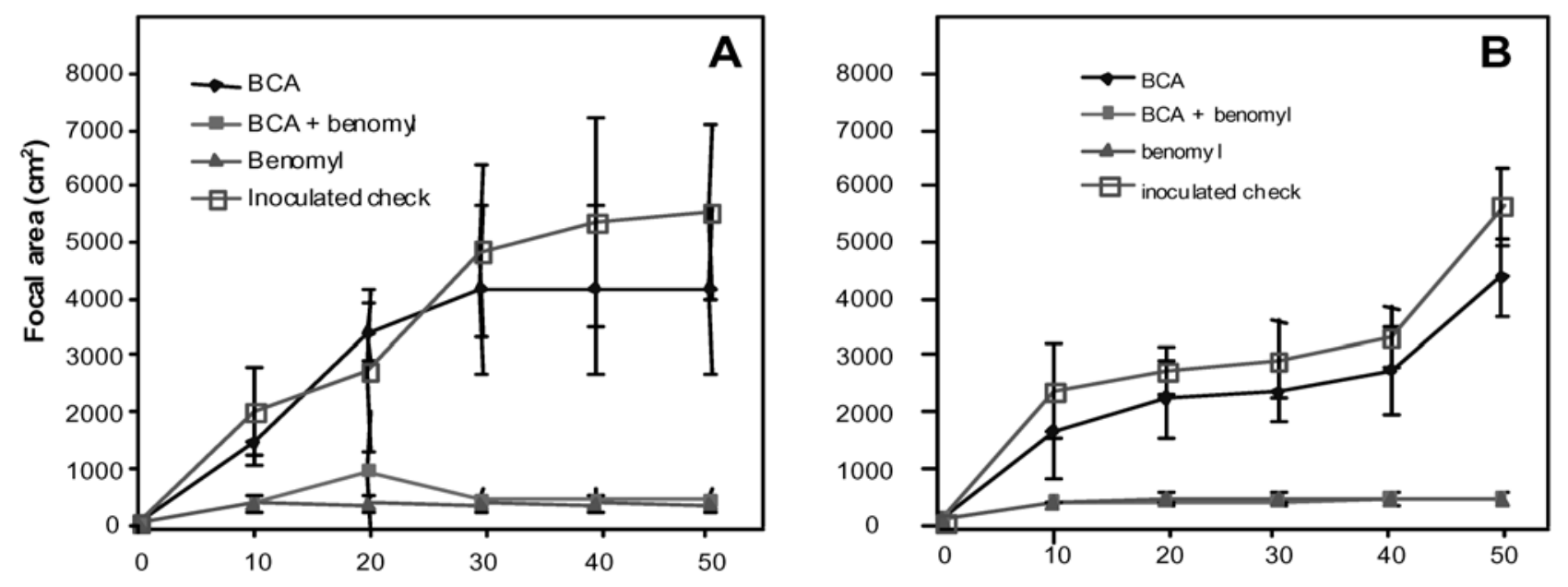

Days after inoculation

Fig. 6. Focal expansion of Rhizoctonia solani AG-1 on artificially inoculated IR72 with one-time application of Pseudomonas fluorescens strain In-b-7-14 during the A, 2001 wet and B, 2002 dry seasons at the International Rice Research Institute. 
university to produce the amount of BCA fermented product in liquid form needed for each crop season over the key sites. The total amount should be available to cover the total area in the large-scale experiments. To formulate the BCA product, one should bear in mind the information of local crop production practices and farmers' crop-management requirements; whereas, in mass production, it is necessary to consider how to minimize storage and shelflife problems for the BCA. Our goal was to deliver $\mathrm{BCA}$ products to rice farmers for their use in crop and disease management during the crop season; therefore, the supply was estimated on a demand basis. Prior to setting the large-scale field experiments, a few practical issues need to be addressed. How and when do farmers need to apply BCAs in relation to their standard crop and disease management? How do we establish the benchmark to measure the efficacy of a promising BCA product in farmers' field? How do we compare the technology of biological control to fungicide or other control measures? What are the essential steps to scale-up the BCA production technology for the resource-poor rice farmers? Could we enhance the naturally occurring BCAs in the rice ecosystems, in both diversity and density, or do we have to rely on the introduction from an alien source through a fungicidal approach?

Farmers' confidence in the technology was a prerequisite for scaling up the BCA production technology. This was built on farmers' participation in product evaluation. "Seeing is believing" and "doing is believing" were the guiding principles to make farmers adopt and integrate BCAs into their crop-management practices. To demonstrate that the technology is "friendly" to increase yield and reduce fungicide use, farmers should participate. Practically, the product has to be low cost, effective, and simple to use. On the premise that we first identified the "key sites" where sheath blight was known to be prevalent and caused damage to farmers' crop production, the efficacy of BCA product and the commonly used fungicides and other control measures were evaluated at the same sites which showed that BCAs caused a reduction in sheath blight incidence (Table 2) and increase in yield (Table 3). Engaging local extension agents and farmers early in the research and technology development was a key to the success of scaling up the technology. Participation is an assurance of believing and also is a way of empowering farmers on BCA technology. The consistency of BCA application in sheath blight management was a major limitation of using BCAs; therefore, we focused on BCA formulation (a mixture of $\mathrm{BCA}$ and fungicide), and we stressed the long-term effect and the sustainable disease and crop-management strategy in the field experiments. In formulations, we stressed BCA strain mixtures and combination of BCAs and a half dose of a common fungicide.

With these considerations, large-scale field experiments of the BCA strain B-916 (a strain of B. subtilis) were carried out for sheath blight control in Jiangsu, China, focusing on three major sites (three counties), and these three sites covered $50 \%$ of rice production in the province of Jiangsu. B. subtilis strain B-916 was produced under the supervision of scientists at the Institute of Plant Protection Research, Jiangsu Academy of Agricultural Sciences (JAAS), who also maintained the strains and offered quality control during the mass production. The amount of production was in response to the demand of the farmers, based on the numbers of fields and the total area needed. Initially, the Plant Protection Institute of JAAS, in collaboration with the Unit of Microbial Fermentation Plant, Nanjing Agricultural University, produced the amount needed for that year. In 1997, the total volume of B-916 fermented product (in liquid form) was 10 tons. While evaluating the formulation and efficacy of strain B-916 with participation of rice farmers at the sites, field-days-cumworkshops also were organized to involve local government authorities and national and international experts to assess the research experiments. Their assessment, together with the data generated over the past few years, were used to apply for registration of the strain and the product. In 1999, strain B-916 was registered for commercialization and, in 2001, a commercial product under the trade name "Wenquning" was pushed into the market. During the first year of its commercial production, 200 tons were produced to cover an area of approximately 67,000 ha (Fig. 7) and it appeared that the market required more than this amount. Because of storage and shelf-life problems, the total amount was produced solely based on market demand. Eventually, JAAS decided to establish a biological control center to produce and market the products of different formulations and strains. This arrangement was feasible because new strains and formulations would continue to be devel-

Table 3. Rice yield as affected by the application of antagonistic bacterium Bacillus subtilis B-916 on Rhizoctonia sheath blight in farmers' fields at three sites in Jiangsu province, China

\begin{tabular}{lcccc}
\hline & & \multicolumn{3}{c}{ Yield $^{\mathbf{z}}$} \\
\cline { 3 - 5 } Year, treatment & Dosage $\left(\right.$ liter ha $\mathbf{~}^{-1}$ ) & Jurong & Jiangyan & Wujiang \\
\hline 1996 & & & & \\
B-916 & $3.75-4.50$ & $8,664 \mathrm{a}$ & $9,225 \mathrm{a}$ & $9,195 \mathrm{a}$ \\
Jingangmycin & $3.75-4.50$ & $8,457 \mathrm{a}$ & $9,330 \mathrm{a}$ & $9,360 \mathrm{a}$ \\
Check & $\ldots$ & $7,581 \mathrm{~b}$ & $7,290 \mathrm{~b}$ & $7,590 \mathrm{~b}$ \\
B-916 & 4.50 & $8,536 \mathrm{~b}$ & $\ldots$ & $\ldots$ \\
B-916 + Jingangmycin & $2.25+2.25$ & $\ldots$ & $9,184 \mathrm{a}$ & $9,162 \mathrm{a}$ \\
1997 & & & & \\
Jingangmycin & 4.50 & $8,424 \mathrm{~b}$ & $9,262 \mathrm{a}$ & $9,255 \mathrm{a}$ \\
Check & $\ldots$ & $7,029 \mathrm{a}$ & $7,949 \mathrm{~b}$ & $7,605 \mathrm{~b}$ \\
\hline
\end{tabular}

${ }^{\mathrm{z}}$ Each yield datum is a mean of six replications. Means in a column within the same year having the same letter are not significantly different from each other $(P>0.01)$ by Duncan's multiple range test.

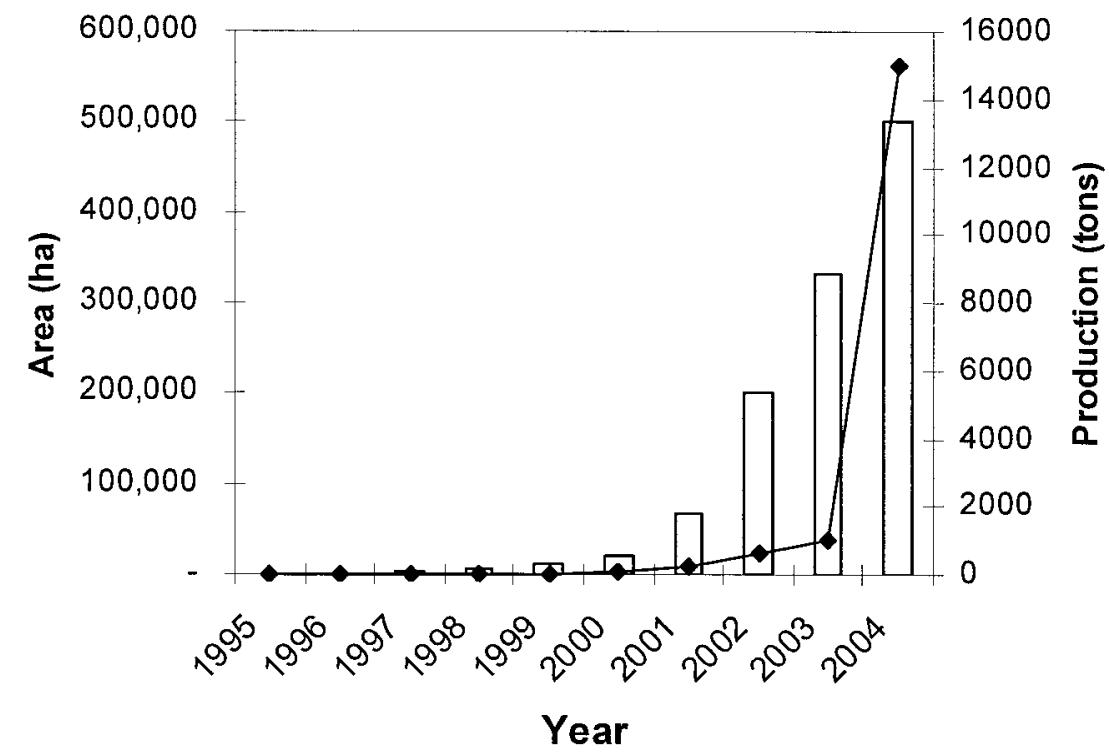

Fig. 7. Riceland area applied (bar graph) with Bacillus subtilis strain B-916 from 1995 to 2002 and projected area for expansion for 2003-04 in Jiangsu, China. Line graph shows the total production of B-916 in tons. 
oped and introduced to rice farmers in the province. In Vietnam, a fermentor with a 10 - to $100-$ liter capacity was designed locally and used at the village level. The farm community owns the fermentor, and production of the BCAs was supervised by agricultural and crop protection technicians while the scientists continued to maintain the strains for use in production and assured the quality of the product.

If plant breeders continue to breed new cultivars every year, there is no reason that plant pathologists should expect one BCA strain or formulation to be enough to solve the entire problem of disease management using BCAs (J. Cook, personal communication). Therefore, BCA technology development should take a long-term view and approach to continue the development of new strains and new formulations.

\section{Conclusion}

Rice ecosystems are rich in microorganisms. Many of these microorganisms are beneficial not only as biological control agents against rice fungal pathogens but also as plant growth-promoting agents in terms of seed germination and seedling vigor. BCAs were found to be effective in reducing the expansion of disease focal point in short-term trials and the number of disease foci in long-term trials. For resource-poor rice farmers, the biological control technology was not readily accepted due to the following technical deficiencies of BCAs found in our research. The performance of BCAs often was inconsistent, such that the efficacy against a target disease such as Rhizoctonia sheath blight was good in one trial but failed to demonstrate the same effect in another trial. However, formulating the BCA product with an additional dose of a commonly used fungicide improved the efficacy and reduced the variance of the tests. This increased the confidence of local technicians to promote the technology. To scale-up the technology, in addition to the required procedures of registration, other difficulties must be considered, such as storage and shelf-life problems. Because of such problems, resource-poor rice farmers are not willing to invest in the application of the product. A system was designed to use locally available resources and mass produce the BCA locally, based on a demand-andsupply system established with local agencies. The field performance trials were conducted in close collaboration with county agricultural technicians to identify key farmers at key sites. Based on the formulation for mass production and the system for delivering the product, BCAs were produced based on the total amount demanded by participating farmers, and the product was used within a single cropping season. Data obtained from the field trials also pro- vided a solid foundation for registration to eventually commercialize the BCA strains together with the formulation. Thus, the system was able to eliminate the problems of storage and shelf life of the BCA.

\section{LITERATURE CITED}

1. Berger, F., Li, H., White, D., Frazer, R., and Leifert, C. 1996. Effect of pathogen inoculum, antagonist density, and plant species on biological control of Phytophthora and Pythium damping-off by Bacillus subtilis Cot 1 in highhumidity fogging glasshouses. Phytopathology 86:428-433.

2. Blakeman, J. P. 1985. Ecological succession of leaf surface microorganisms in relation to biological control. Pages 6-30 in: Biological Control in the Phyllosphere. C. E. Windels and S. E. Lindow, eds. The American Phytopathological Society, St. Paul, MN.

3. Chen, Z. Y., Guo, C. J., and Yang, J. S. 1989. The relationship between sheath blight severity and yield loss of rice cultivars. Acta Phytopathol. Sin. 16:49-54.

4. Chen, Z. Y., Xu, Z. G., Gao, T. D., Ni, S. K., Yan, D. F., Lu, F., and Liu, Y. F. 2001. Biological control of rice diseases. Pages 61-63 in: Seed Health and Seed-associated Microorganisms for Rice Disease Management. T. W. Mew and B. Cottyn, eds. International Rice Research Institute, Los Baños, Philippines.

5. Chen, Z. Y., Yin, S. Z., Lu, F., and Li, Z. P. 1996. Screening and utilization of antagonistic bacteria for rice sheath blight control. Pages 15 in: Advances in Biological Control of Plant Diseases. W. H. Tang, R. James Cook, and A. Rovira, eds. China Agricultural University Press, Beijing.

6. Cottyn, B., Regalado, E., Lanoot B, De Cleene, M., Mew, T. W, and Swings, J. 2001. Bacterial populations associated with rice seed in the tropical environment. Phytopathology 91:282-292.

7. Duineveld, B. M., Rosado, A. S., van Elsas, J. D., and van Veen, J. A. 1998. Analysis of the dynamics of bacterial communities in the rhizosphere of the Chrysanthemum via denaturing gradient gel electrophoresis and substrate utilization pattern. Appl. Environ. Microbiol. 64:4950-4957.

8. Elson, M. K., Schister, D. A., and Bothast, R. J. 1997. Selection of microorganisms for biological control of silver scurf (Helminthosporium solani) of potato tubers. Plant Dis. 81:647-652.

9. Gnanamanickam, S. S., and Mew, T. W. 1992. Biological control of blast disease of rice (Oryza sativa L.) with antagonistic bacteria and its mediation by a Pseudomonas antibiotic. Ann. Phytopathol. Soc. Jpn. 58:380-385.

10. Guo, C. J., and Chen, Z. Y. 1992. On the control strategy of rice sheath blight caused by Thanatephorus cucumeris in China. Jiangsu J. Agric. Sci. 8:36-39.

11. Kobayashi, T., Mew, T. W., and Hashiba, T. 1997. Relationship between incidence of rice sheath blight and primary inoculum in the Philippines: Mycelia in plant debris and sclerotia. Ann. Phytopathol. Soc. Jpn. 63:324-327.

12. Kozaka, T. 1961. Ecological studies on sheath blight of rice plant caused by Pellicularia sasakii and its chemical control. Chugoku Agric. Res. 20:1-13

13. Lee, F. N. 1980. Number, viability, and buoyancy of Rhizoctonia solani sclerotia in Arkansas rice fields. Plant Dis. 64:298-300.

14. Mew, T. W., and Rosales, A. M. 1986. Bacterization of rice plants for control of sheath blight caused by Rhizoctonia solani. Phytopathology
76:1260-1264.

15. Mew, T. W., and Rosales, A. M. 1992. Control of Rhizoctonia sheath blight and other diseases by rice seed bacterization. Pages 113-123 in: Biological Control of Plant Diseases. E. S Tjamos, G. C. Papavizas, and R. J. Cook, eds. Plenum Press, New York.

16. Mew, T. M., Rosales, A. M., and Maningas, G. V. 1994. Biological control of Rhizoctonia sheath blight and blast of rice. Pages 9-13 in: Improving Plant Productivity with Rhizosphere Bacteria. M. H. Ryder, P. M. Stephens, and G. D. Bowen, eds. Graphic Services, Adelaide, Australia.

17. Nilpanit, N., Aruryanart, R. P., and Mew, T. W. 2001. Sustaining biological control in farmers fields. Pages 55-59 in: Seed Health and Seedassociated Microorganisms for Rice Disease Management. T. W. Mew and B. Cottyn, eds. International Rice Research Institute, Los Baños, Philippines.

18. Ou, S. H. 1985. Rice Diseases. 2nd ed. Commonwealth Mycological Institute, Kew, England.

19. Pierson, E. A., and Weller, D. M. 1994. Use of mixtures of fluorescent Pseudomonads to suppress take-all and improve the growth of wheat. Phytopathology 84:940-947.

20. Pingali, P. L, Marquez, C. B., and Rola, A. C. 1995. The impact of long-term pesticide exposure on farmer health: A medical and economic analysis. Pages 343-390 in: Impact of Pesticides on Farmer Health and the Environment P. L. Pingali and P. A. Roger, eds. International Rice Research Institute, Los Baños, Philippines.

21. Rosales, A. M., and Mew, T. W. 1997. Suppression of Fusarium moniliforme in rice by rice-associated antagonistic bacteria. Plant Dis. 81:49-52.

22. Rosales, A. M., Thomashow, L., Cook, R. J., and Mew, T. W. 1995. Isolation and identification of antifungal metabolites produced by rice-associated antagonistic Pseudomonas spp. Phytopathology 85:1028-1032.

23. Rosales, A. M., Vantomme, R., Swings, J., De Ley, J., and Mew, T. W. 1993. Identification of some bacteria from paddy antagonistic to several fungal pathogens. J. Phytopathol. 138:189-208.

24. Savary, S., Castilla, N. P., Elazegui, F. A., McLaren, C. G., Ynalvez, M. A., and Teng, P. S. 1995. Direct and indirect effects of nitrogen supply and disease source structure on rice sheath blight spread. Phytopathology 85:959965.

25. Savary, S., Willocquet, L., Elazegui F. A., Teng, P. S., Du, P. V., Zhu, D., Tang, Q., Huang, S., Lin, X., Singh, H. M., and Srivastava, R. K. 2000. Rice pest constraints in tropical Asia: Characterization of injury profiles in relation to production situations. Plant Dis. 84:341-356.

26. Schisler, D. A., Slininger, P. J., and Bothast, R. J. 1997. Effects of antagonist cell concentration and two-strain mixtures on biological control of Fusarium dry rot of potatoes. Phytopathology 87:177-183.

27. Thompson, D. C., Clarke, B. B., and Kobayashi, D. Y. 1996. Evaluation of bacterial antagonists for reduction of summer patch symptoms in Kentucky bluegrass. Plant Dis. 80:856-862.

28. Utkhede, R. S., and Rahe, J. E. 1983. Interactions of antagonist and pathogen in biological control of onion white rot. Phytopathology 73:890-893.

29. van Veen, J. A., van Overbeek, L. S., and van Elsas, J. D. 1997. Fate, and activity of microorganisms introduced to soil. Microbial Mol. Biol. Rev. 61:121-135. 